\title{
A PRELIMINARY NUMERICAL STUDY OF HEAT TRANSPORT DURING IN SITU VITRIFICATION OF SOIL
}

\author{
Paul E. Murray \\ Grant L. Hawkes \\ Robert J. MacKInnon
}

Published June 1990

EG\&G Idaho, Inc.

Idaho Falls, Idaho 83415 
A PRELIMINARY NUMERICAL STUDY OF

HEAT TRANSPORT DURING IN SITU VITRIFICATION OF SOIL

EGG -WM- 9038

Approved By:

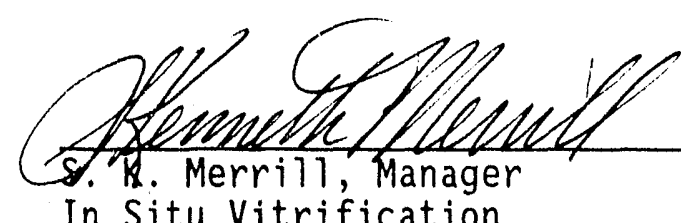

Date: $9 / 17 / 90$

In Situ Vitrification

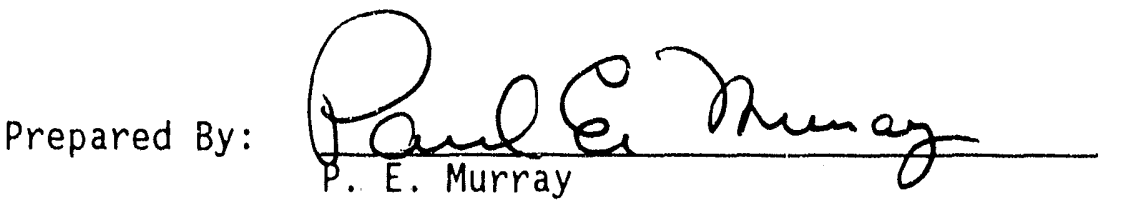

Date: $9 / 14 / 90$

Approved By:

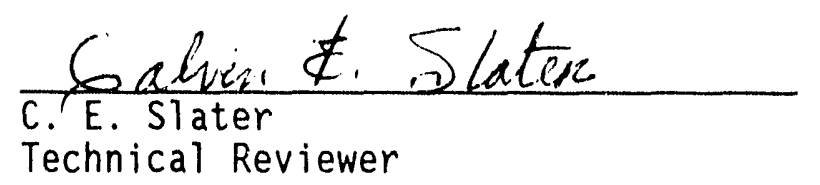

Date: $14 \operatorname{sen} 90$ 


\begin{abstract}
A numerical study of heat transport during in situ vitrification is presented. We simulate the soil temperature and melting rate, and the calculations agree well with exporimental data. This is the first in a series of numerical studies, in which we analyze specific aspects of the vitrification process.
\end{abstract}




\section{CONTENTS}

INTRODUCTION $\ldots \ldots \ldots \ldots \ldots \ldots \ldots \ldots \ldots \ldots \ldots \ldots \ldots \ldots \ldots \ldots \ldots \ldots \ldots \ldots \ldots \ldots$

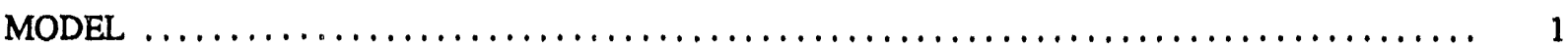

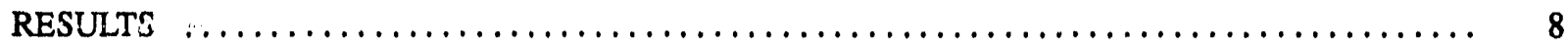

\section{FIGURES}

1. Geometry for an axisymmetric simulation of the in situ vitrification process $\ldots \ldots \ldots \ldots \ldots 2$

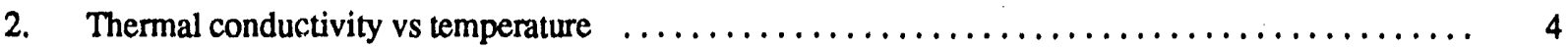

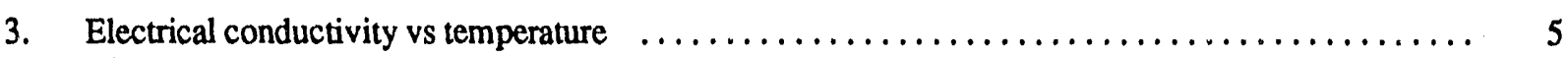

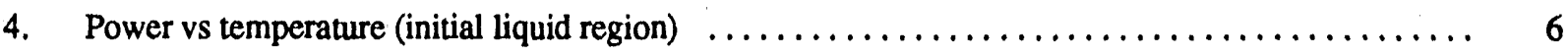

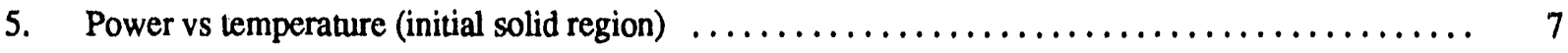

6. Finite element mesh; the cross-sectional area is $20 \times 20 \mathrm{~m} \ldots \ldots \ldots \ldots \ldots \ldots \ldots \ldots$

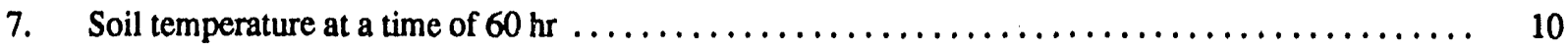




\section{A PRELIMINARY NUMERICAL STUDY OF HEAT TRANSPORT DURING IN SITU VITRIFICATION OF SOIL}

\section{INTRODUCTION}

The process of soil vitrification has been developed to contain the hazardous wastes buried underground. This is achieved by melting the soil using electrical resistance heating and allowing it to solidify into a vitreous, or glassy solid. As a consequence of this treatment, the hazardous wastes are held in the vitrified soil so that its harmful effect on the environment is reduced.
A preliminary numerical study of soil melting is performed. The aim is to use a sinıplified mathematical model to simulate the soil temperature and the melting rate. Based on experimental data, the soil temperature reaches a maximum of about $2000^{\circ} \mathrm{C}$ and the melting rate is about $2-3 \mathrm{~cm}$ per hour. We consider a representative vitrification process taking 60 hours and obtain results that agree well with experimental data.

\section{MODEL}

We consider a region of soil whose cross-sectional geometry is illustrated in Figure 1. The calculation is performed with an axisymmetric coordinate system $(r, \theta, z)$ and we obtain a two-dimensional problem by assuming that the temperature is independent of the $\theta$ coordinate. We assume that there is initially a small region, a square having an area of $1 / 9 \mathrm{~m}^{2}$, in which the soil is at its melting temperature. The rest of the soil is initially at ambient temperature.

As a result of electrical resistance heating, the soil temperature increases above the melting point. Heat energy is lost to the air by radiation and convection. At the other three surfaces of the region, in which two are far from the heat source ainu une is an axis of symmetry, we may assune inat there is no heat flux. by

The governing equation of heat conduction ${ }^{\mathrm{a}}$ is given

$$
\begin{aligned}
e c_{p} \frac{\partial T}{\partial t} & -\frac{1}{r} \frac{\partial}{\partial r}\left(r k(T) \frac{\partial T}{\partial r}\right) \\
& -\frac{\partial}{\partial z}\left(k(T) \frac{\partial T}{\partial z}\right)=Q(T)
\end{aligned}
$$

a. J. P. Holman, Heat Transfer, McGraw--Hill, NY, 1976. where $T(r, z, t)$ is the temperature, $t$ is the time, $\rho$ is the density, $c_{p}$ is the heat capacity, $k$ is the thermal conductivity and $Q$ is the electrical heat source. Equation (1) is assumed to hold in a square region having sides of length $L=20 \mathrm{~m}$.

For electrical resistance heating, $Q$ is given by

$Q(T)=\frac{l^{2}}{k_{c}(T)}$

where $i$ is the current density and $k_{e}$ is the electrical conductivity.

The current density may be obtained from the solution of the electrostatic potential equation. For this preliminary numerical study, we have chosen to use a simplified mathematical representation of the electrical heat source. In particular, the current density is assumed to have a constant value which is determined from a measured average electrical power. Although this is an unsophisticated approximation, it provides a heat source model to investigate solutions of Equation (1). This model is not capable of precisely simulating an ISV process, and is limited to numerical studies in which we examine the dominant physical phenomena and assess the performance of numerical methods.

Boundary conditions for Equation (1) are

$\frac{\partial T}{\partial r}(0, z, t)=\frac{\partial T}{\partial r}(L, z, t)=\frac{\partial T}{\partial z}(r, L, t)=0$ 


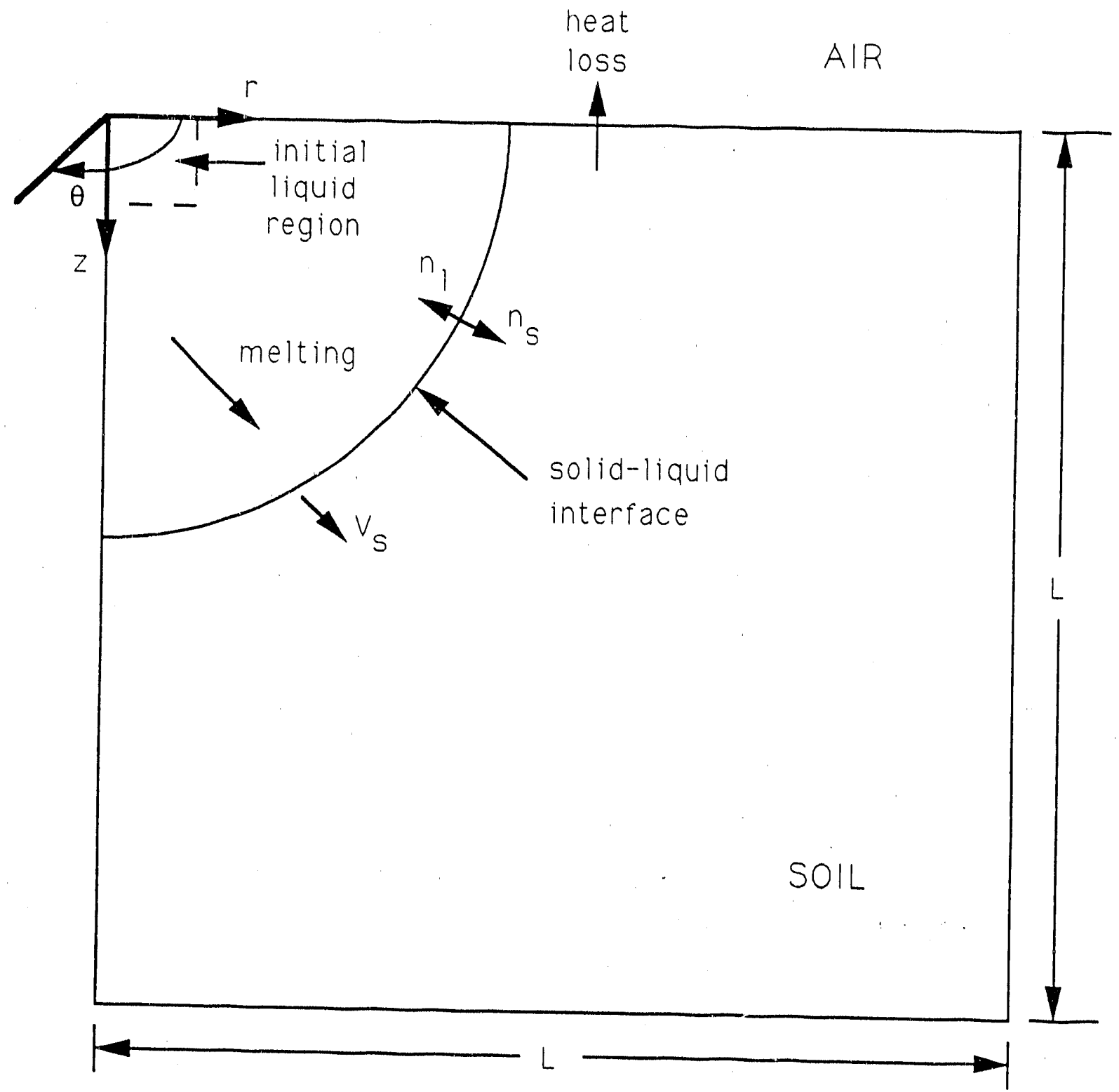

Figure 1. Geometry for an axisymmetric simulation of the in situ vitrification process.

and

$-k \frac{\partial T}{\partial z}(r, 0, t)=h\left[T(r, 0, t)-T_{a}(r, t)\right]$

where $T_{a}$ is the ambient air temperature and $h$ is the total heat transfer coefficient given by

$h=h_{c}+h_{r}$

where $h_{c}$ and $h_{r}$ are the convective and radiative heat transfer coefficients.
Boundary conditions at the liquid-solid interface are given by

$T\left(r^{m}, z^{m}, t\right)=T_{m}$

$k\left(T_{m}\right) \frac{\partial T}{\partial n_{s}}\left(r^{m}, z^{m}, t\right)+k\left(T_{m}\right) \frac{\partial T}{\partial n_{l}}\left(r^{m}, z^{m}, t\right)$

$=Q L V_{s}$

where $r^{m}, z^{m}$ are the coordinates of the liquid-solid interface, $T_{m}$ is the melting temperature, $L$ is the heat of fusion, $n_{l}$ and $n_{s}$ are unit vectors normal to the interface 
that point into the liquid and solid, and $V_{s}$ is the melting rate.

The convective heat transfer coefficient ${ }^{\mathrm{a}}$ from a heated surface to air is given by

$$
h_{c}=\frac{k}{\delta} 0.332 \operatorname{Pr}^{\frac{1}{3}} \operatorname{Re}^{\frac{1}{2}}
$$

in which the properties are those of air. The Prandtl number $P r$ is given by

$$
\operatorname{Pr}=\frac{\mu c_{p}}{k}
$$

and the Reynolds number Re is given by

$$
\operatorname{Re}=\frac{\rho V \delta}{\mu}
$$

where $V$ is the air velocity and $\delta$ is a characteristic length scale that we set equal to the electrode separation. The properties of air are evaluated at the tempera. ture which is the average of the soil surface and ambient air temperatures. For a soil temperature of $1200^{\circ} \mathrm{C}$, an air temperature of $200^{\circ} \mathrm{C}$ and an air pressure of $20 \mathrm{~atm}$, with $V$ equal to $10 \mathrm{~m}$ per sec and $\delta$ equal to $4 \mathrm{~m}$, we obtain from equations (8)-(10) that $h_{c}$ is $13 \mathrm{~W} / \mathrm{m}^{2}{ }^{\circ} \mathrm{C}$.

The radiation heat transfer coefficient $h_{r}$ is given by

$$
h_{r}=\sigma \epsilon\left(T^{2}+T_{a}^{2}\right)\left(T+T_{a}\right)
$$

where $\sigma$ is the Stefan-Boltzmann constant and $\epsilon$ is the emissivity of soil. For a temperature difference $T$ $T_{a}$ equal to $1000^{\circ} \mathrm{C}$, we obtain from Equation (11) that $h_{r}$ is $250 \mathrm{~W} / \mathrm{m}^{2}{ }^{\circ} \mathrm{C}$, so that radiative heat loss will dominate convective heat loss.

The ambient air temperature $T_{a}$ is given by

$$
T_{a}(r, t)=\frac{1}{6} T(r, 0, t)
$$

for $r<2 m$, and $T_{a}(r, t)=0^{\circ} \mathrm{C}$ for $r>2 \mathrm{~m}$. This accounts for the presence of a containment hood at $r=0$ to

a. Holman, Heat Transfer. $r=2 m$, in which the maximum temperature is assumed to be $200^{\circ} \mathrm{C}$.

The properties of soil ${ }^{b}$ are given by

$$
\begin{aligned}
& Q=2.2 * 10^{3} \mathrm{~kg} / \mathrm{m}^{3} \\
& c_{p}=1 *^{*} 10^{3} \mathrm{j} / \mathrm{kg}^{\circ} \mathrm{C} \\
& T_{m}=1200^{\circ} \mathrm{C} \\
& L=2.4 * 10^{5} \mathrm{j} / \mathrm{kg} \\
& \epsilon=0.94
\end{aligned}
$$

The temperature dependence of the thermal conductivity $k$ and electrical conductivity $k_{e}$ are shown in Figures 2 and 3.

The current density is assumed to have a constant value which is determined from a measured average electrical power density. Using Equation (2) and evaluating the electrical conductivity at $T=T_{m}$ and setting $Q=1.3^{*} 10^{5} \mathrm{~W} / \mathrm{m}^{3}$, which is an experimentally determined average electrical power density, we obtain $l=$ $0.36^{*} 10^{3} \mathrm{~A} / \mathrm{m}^{2}$.

We obtain the heat source $Q$ by substituting into Equation (2) the average current density. The temperature and position dependence of the heat source is shown in Figures 4 and 5. The position dependence accounts for the presence of a region of soil that is initially liquid.

The finite element mesh used for the calculation is shown in Figure 6 . The grid size is small in the region that is initially liquid, in order to calculate accurately the sharp transition from melting to ambient temperature.

b. The properties of soil at high temperature were obtained from Buelt et al, "In-situ Vitrification of Transuranic Wastes: An Updated Systems Evaluation and Applications Assessment," Pacific Northwest Laboratory Technical Report, March 1987. There is an uncertainty in these values, because of the difficulty of making high temperature measurements and the variability of soil composition. So there is a need to devise experiments from which to obtain accurate values of INEL soil properties at high temperature. 


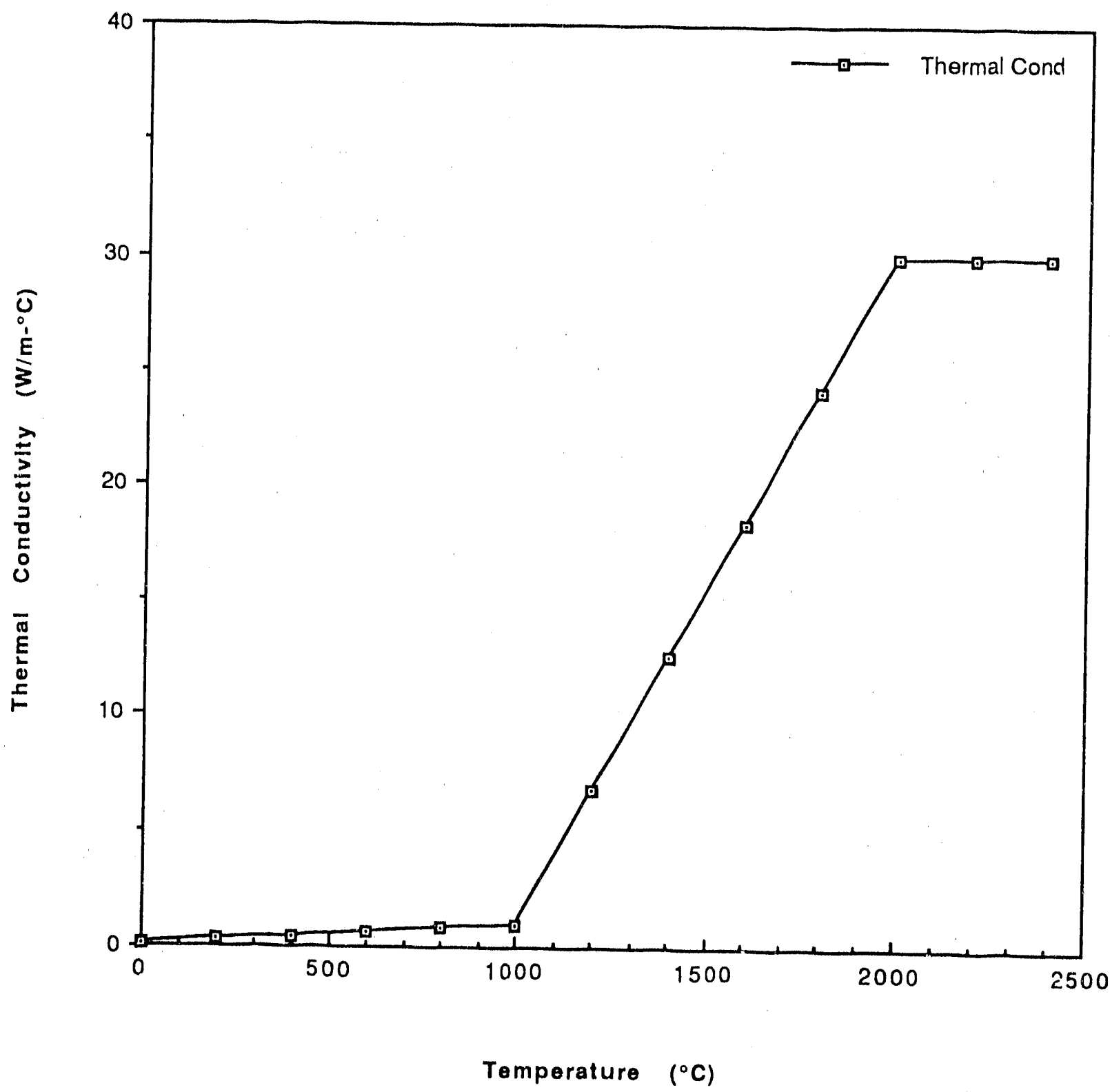

Figure 2. Thermal conductivity vs temperature. 


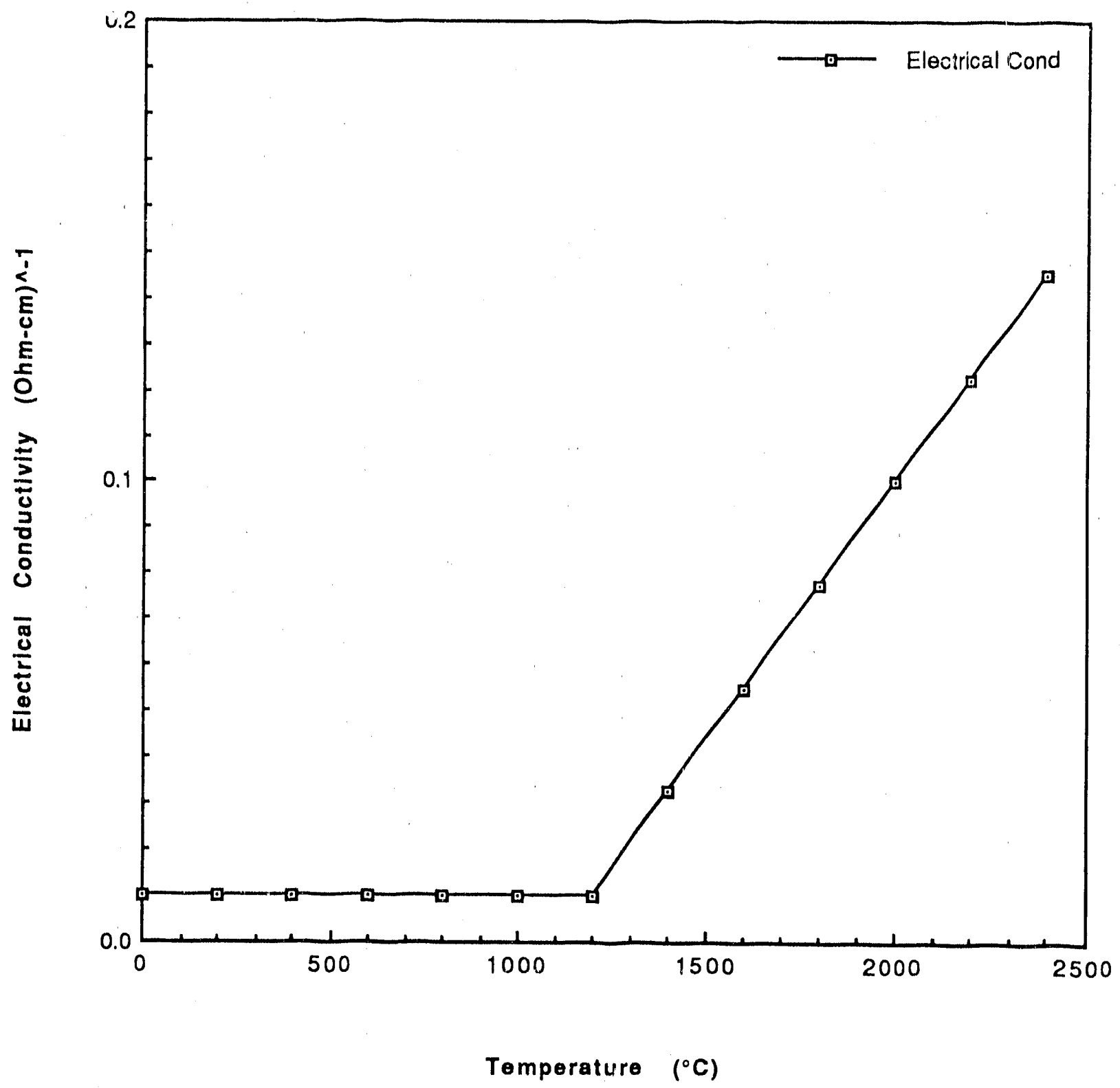

Flgure 3. Electrical conductivity vs temperature. 


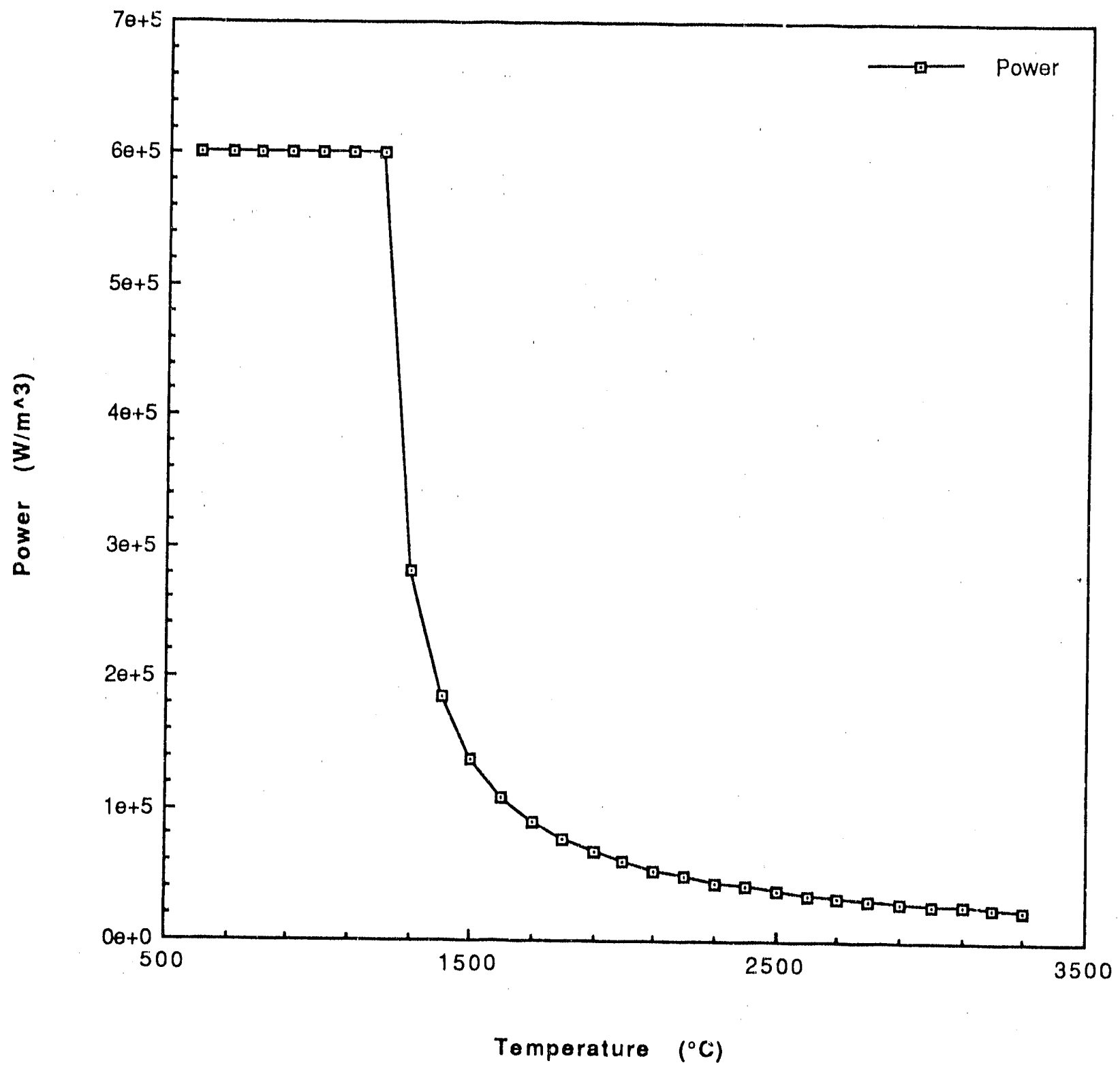

Figure 4. Power vs temperature (initial liquid region). 


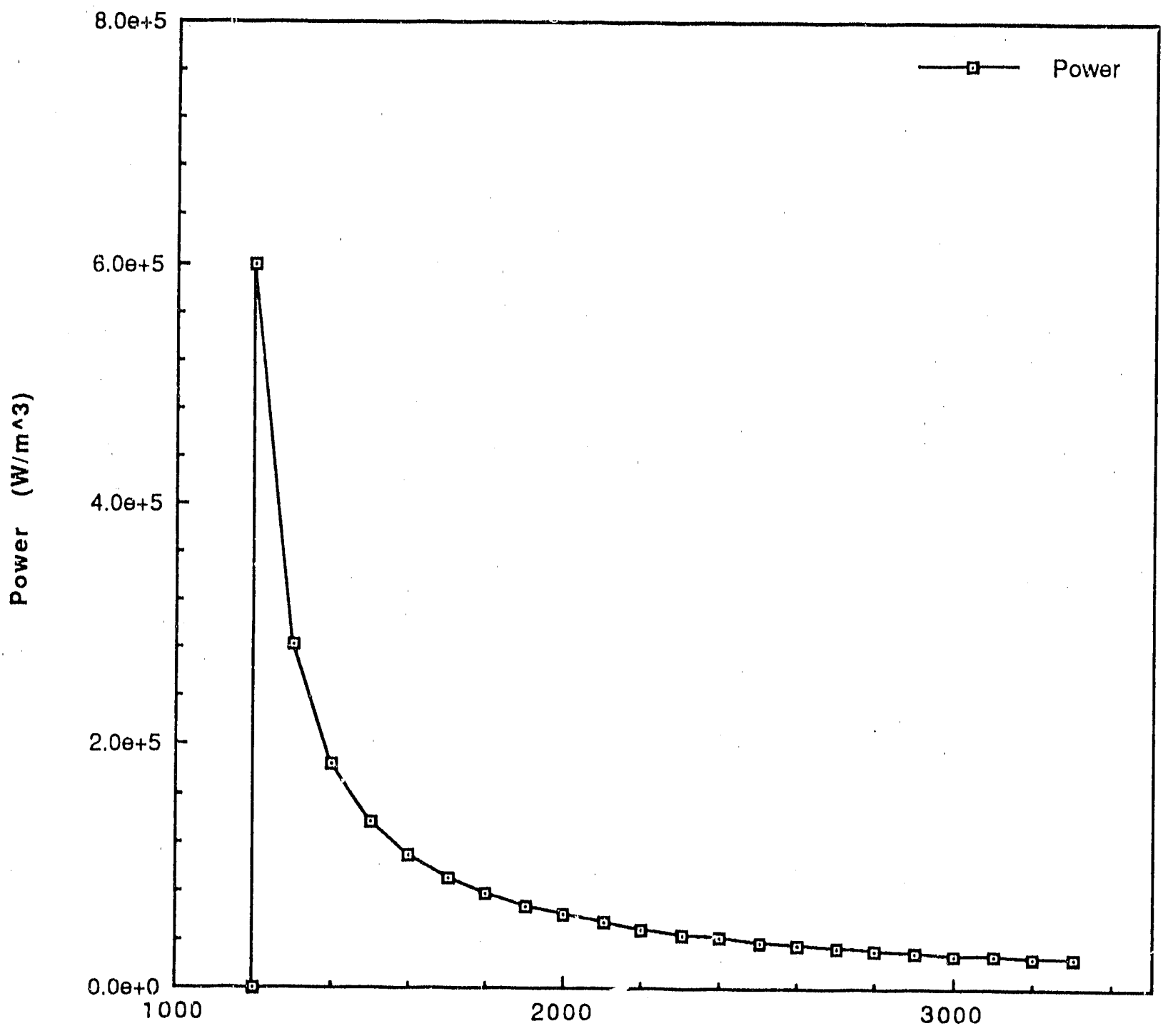

Temperature $\left({ }^{\circ} \mathrm{C}\right)$

Flgure 5. Power vs temperature (initial solid region). 


\section{RESULTS}

We have simulated heat transport and melting to a time of 60 hours, and we show in Figure 7 the temperature contours that correspond to the final time. The melted soil region has grown to a depth of about $2 \mathrm{~m}$, and growth is more rapid in the vertical direction thar the horizontal direction. This occurs hecause there is a large heat loss by radiation to the air. Also because of heat loss, the soil near the ground si rface has solidified, producing a solid cap above the liquid melt. 'The region of high temperature moves downward as the soil melts, and there is a sharp transition from high to low temperature that occurs near the liquid-solid interface. The solid soil, about a half meter away from the interface, is at ambient temperature.

We have obtained $2.5 \mathrm{~cm}$ per hour for the average melting rate and a maximum temperature of about $2000^{\circ} \mathrm{C}$, and these values agree well with experimental measurements. The ability to simulate heat transport and melting is essential for modeling in situ vitrification, because many phenomena that occur during vitrification are sensitive to temperature changes. This simulation capability will be used to aid in assessing the performance and safety of the process. 


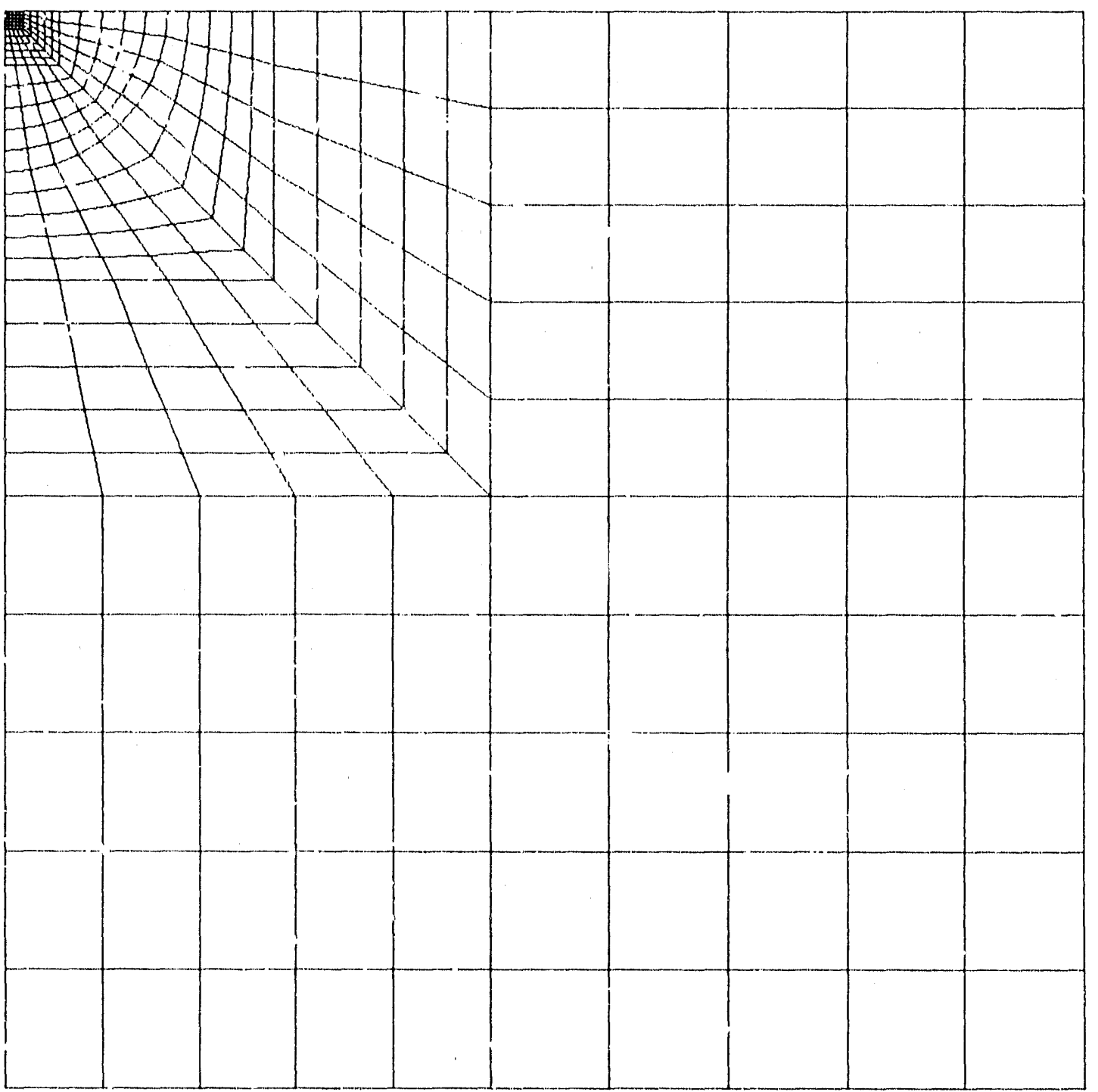

Figure 6. Finite element mesh; the cross-sectional area is $20 \times 20 \mathrm{~m}$. 


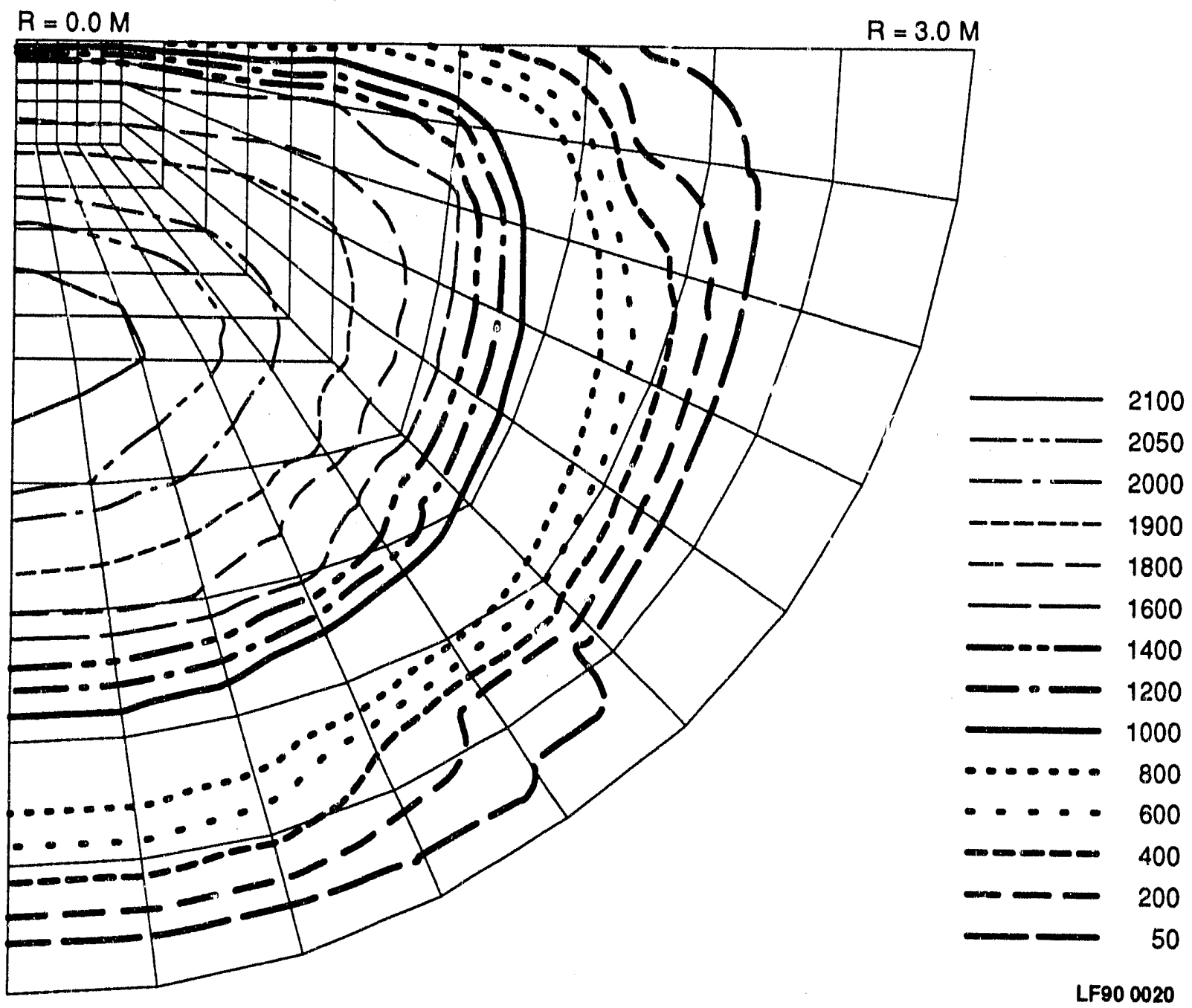

Figure 7. Soil temperature at a time of $60 \mathrm{hr}$. 

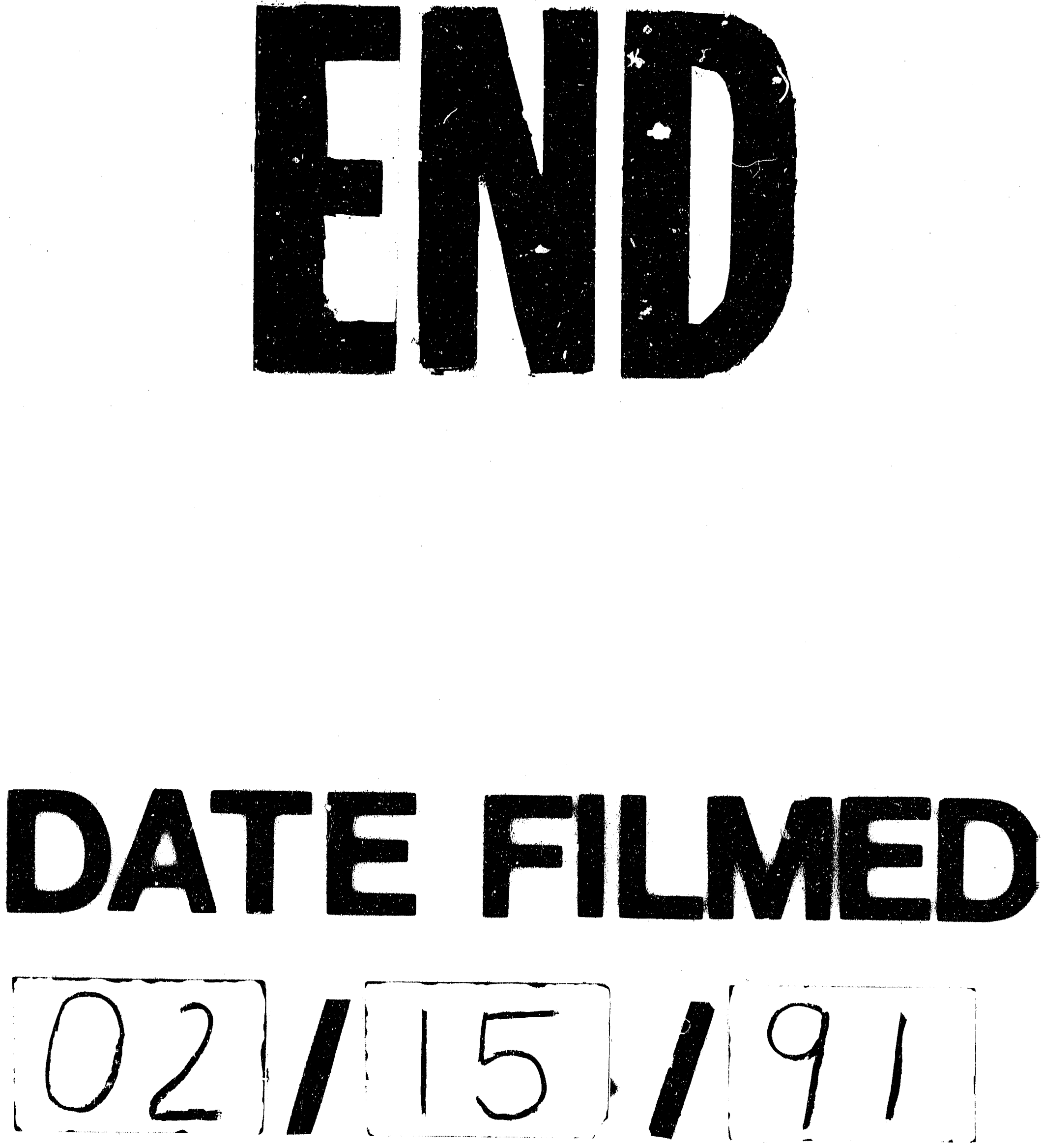
. " . . . . " n 